\title{
LA CONCEPCIÓN DEL HOMBRE DE FRIEDRICH HAYEK*
}

\author{
Jorge Vergara Estévez \\ Universidad de Chile \\ vergaraestevez@gmail.com
}

\begin{abstract}
Resumen
En este artículo se ofrece una presentación de los aspectos centrales de la concepción del hombre de Hayek y una breve reflexión sobre ella. Primero, se expone su concepción de lo que es el hombre: un ser individualista, cuya evolución histórica conduce a la "sociedad extendida", y creador de normas y tradiciones. A continuación, se caracterizan sus principales dimensiones: la ética es heterónoma y coincide con las reglas sociales; su razón es limitada; la libertad es individual, negativa, y se limita a la libertad económica y, finalmente, sostiene que los hombres son naturalmente desiguales.
\end{abstract}

PalABRAS ClaVE: antropología, individualismo, concepción evolutiva, ética inmanente, libertad e igualdad.

\begin{abstract}
We explain the main aspects of Hayek's conception of man and its intellectual background. The Austrian thinker developed this conception on two levels. On the one hand, he proffers an idea of what man is, namely, an individualist, who evolves from "tribal society" to "extended society", and a creator of norms and traditions. On the other had, he tells how man is, he spells out his chief characters: man's ethics is heteronomous and immanent to the reproduction of society; man's intelligence is limited and his central value is freedom, economically understood. Finally, Hayek maintains that me are naturally unequal.
\end{abstract}

KEYWORDS: anthropology, individualism, evolutive conception, immanent ethics, freedom and equality.

\section{Introducción}

RA Hegel decía que toda filosofía era hija de su tiempo y, a la vez, lo expresaba en pensamientos. Sin embargo, la relación entre la filosofía y la cultura de su tiempo ha sido frecuentemente conflictiva. Desde sus orígenes, el pensar filosófico ha estado en relación de diálogo y crítica con otras formas de saber relevantes en

Este artículo sintetiza los resultados del primer año de la realización del proyecto de investigación: "La concepción del hombre de Hayek y la modernidad" No 1071070 de CONICYT. 
la cultura de su tiempo: el mito entre los griegos, el cristianismo en el Medioevo y las ciencias en la modernidad. Es así como la filosofía ha intentado responder a interrogantes abiertos por las teorías científicas, ha contribuido a (re)formularlas o bien los ha cuestionado ${ }^{1}$. La relación entre filosofía y ciencias es mucho más estrecha y directa en los ámbitos de la filosofía política y en la epistemología, en las cuales los límites entre teoría social, epistemológica y filosófica, son permeables o difusos. Muestra de ello es que, durante el siglo XIX y, especialmente, en el siglo pasado, encontramos filósofos que son teóricos sociales como Marx, Horkheimer, Habermas, Ricoeur y Foucault. Asimismo, los filósofos han hecho un importante aporte en la discusión sobre la validez del conocimiento científico y el modelo positivista, el cual sostiene que las ciencias han llegado a ser solo conocimiento empírico, ajeno a todo aspecto metafísico. Habermas ha mostrado que las ciencias sociales siguen siendo "teorías" en el sentido griego del saber contemplativo de la sociedad y el cosmos (1964). Heidegger, por su parte, ha relacionado el develamiento del fundamento metafísico de la ciencia con la esencia de la modernidad: "si se logra llegar al fundamento metafísico que fundamenta la ciencia moderna, entonces se podrá desde él conocer la esencia de la Edad Moderna en general" (1958, p. 18). Asimismo, ha aseverado que la física pretende ser meta-física.

Desde el siglo pasado se produce una amplia reflexión filosófica sobre las ciencias naturales, especialmente con Husserl (1984), Whitehead, Russell y Heidegger, pero ésta ha sido menor respecto a las teorías sociales y las teorías económicas. Este artículo tiene por objetivo aportar al conocimiento y reflexión sobre la antropología de Hayek, desde una perspectiva de hermenéutica filosófica, que facilite su comprensión. Esta investigación se justifica por: (a) la importancia del pensamiento del teórico social austriaco; (b) por la necesidad de contar con una sucinta exposición sistemática de su antropología, la cual se desarrolló a través de toda su obra conjuntamente con su teoría social, y la cual el autor no expuso separadamente; y, (c) porque plantea problemas relevantes para la reflexión antropológica contemporánea.

Friedrich Hayek es uno de los principales teóricos sociales del siglo pasado y su importancia es comparable a la de Weber y Keynes. Su influencia es indudable en la teoría económica, pero también en la actual concepción de la democracia, en la concepción del hombre, y en la concepción sobre la globalización (Vergara 2007). En Chile, su pensamiento influyó, desde los setenta, en el de Jaime Guzmán; ha tenido una significativa presencia en los círculos liberales y en la constitución de 1980, especialmente en su concepción de los derechos individuales y de la democracia. Si el período que va desde el fin de la Segunda Guerra hasta mediados de los setenta del

1 Kant, por ejemplo, elaboró una explicación sobre la validez de las leyes de la física clásica, y elaboró una teoría cosmológica. Horkheimer, por su parte, cuestionó la concepción positivista de las ciencias sociales, propuso una nueva epistemología crítica y realizó una crítica a la razón instrumental. 
siglo fue llamado justificadamente "la era de Keynes", los últimos tres decenios podrían ser denominados "la era de Hayek" 2

Se distinguen dos etapas en la obra de Hayek. La primera se extiende desde 1929 a 1941, donde publica cuatro libros de teoría económica ${ }^{3}$. La segunda etapa de sus investigaciones se inicia con el libro El camino de servidumbre, en 1944, y se prolongó hasta su última obra, La fatal arrogancia. Los errores del socialismo, de 1988. En ella, Hayek se convirtió en un teórico social y desarrolló su concepción del hombre, conjuntamente con su teoría de la sociedad, el derecho y del mercado.

Hayek se inscribe en la tradición clásica que proviene de Platón y Aristóteles de fundar la concepción de la sociedad en una teoría antropológica ${ }^{4}$. El referente principal en la elaboración de su antropología fue el liberalismo inglés del siglo XVII y XVIII, especialmente el de Locke y Smith. Los fundadores del liberalismo ofrecieron una salida a la crisis del Estado y la sociedad absolutista del siglo XVII, elaborando una nueva concepción de la sociedad y la política, en el marco de una "sociedad de relaciones mercantiles desarrolladas" (Macpherson 1970). Ellos consideraban que dicho modelo era el único adecuado, porque correspondía a la verdadera naturaleza del hombre, que habían expuesto en sus escritos, la cual no había podido realizarse durante el régimen absolutista. Hayek reactualiza este proyecto teórico, pues también pretende recrear la sociedad, transformarla radicalmente, de acuerdo con su proyecto que contiene una utopía política y social. Para ello, busca un nuevo fundamento de su teoría de la sociedad, la economía y la política, y cree haberlo encontrado en una nueva concepción del hombre.

Esta concepción antropológica está constituida por siete enunciados de alto nivel de abstracción, que sintetizan teorías específicas sobre el hombre. Estas poseen pretensiones de universalidad y son concordantes entre sí. Los tres primeros enunciados responden a la pregunta qué es el hombre, y las cuatro últimos a la pregunta cómo es, es decir, cuáles son sus características principales ${ }^{5}$. Estos enunciados son: (a) el hombre es un individuo; (b) es un ser evolutivo; (c) es un ser creador de normas y tradiciones;

2 Este fue el título de un libro de Robert Leckachman, publicado en la década de los sesenta. Las estructuras políticas y sociales y los modelos de desarrollo se configuran en relación con ciertas teorías sociales que orientan la acción social, cuyos supuestos son aceptados consensualmente, y resulta muy difícil actuar fuera de estos parámetros. Es así como se ha hablado de la era de Marx, de Keynes y de Hayek.

3 Estas son: La teoría monetaria y el ciclo económico (1929), Precios y producción (1931) Economía y conocimiento (1936) y La teoría pura del capital (1941).

4 Como se recordará, Aristóteles funda su filosofía política en una concepción de la naturaleza humana, del hombre como zóon politikón, y como animalis rationalis. Desde esta perspectiva, el hombre es naturalmente social y el orden político tiene por telos no solo hacer posible la vida, sino "una buena vida" de realización de su fin propio.

5 Esta es una distinción clásica de la filosofía griega, y ya aparece explícitamente formulada por Platón en su indagación sobre la virtud en el Menón, y es reelaborada por Aristóteles como "sustancia primera" y "accidentes". 
(d) sus normas éticas principales son funcionales a la sociedad de mercado; (e) su racionalidad es limitada; (f) su libertad individual es negativa, y (g) los hombres son naturalmente desiguales.

El hombre es un individuo. Hayek define su visión del hombre como un "verdadero individualismo" de carácter "irracionalista", en oposición al "falso individualismo" racionalista (1986). Su postura es de carácter nominalista. En su concepción del hombre y la sociedad acepta, parcialmente, el supuesto ontológico sobre el carácter agregatorio de la realidad, la cual no estaría formada por totalidades. La realidad sería la suma de elementos, individuos y acontecimientos coincidentes consigo mismo y que se relacionan externamente. Esta concepción está en la base de la concepción mecanicista del hombre y la sociedad de Hobbes. Su presencia en la teoría de Hayek se debería a la influencia de Popper y a la necesidad de rechazar cualquier argumento en el cual la sociedad aparece como sujeto de deberes. Popper lo formula como criterio teórico-metodológico del "individualismo metodológico". Dice: "todos los fenómenos sociales, y especialmente el funcionamiento de las instituciones sociales, debe ser siempre considerado el resultado de las decisiones, acciones, actitudes de los individuos humanos, y nunca debemos conformarnos con las explicaciones elaboradas en función de los llamados "colectivos" (Estados, naciones, razas, etc.)" (Popper 1981, p. 283). En otro texto señala que "la creencia en la existencia empírica de conjuntos o colectivos sociales, a la que podríamos llamar colectivismo ingenuo, debe ser remplazada por el requisito de que los fenómenos sociales, inclusive los colectivos, sean analizados en función de los individuos, sus acciones y relaciones" (Popper 1989, p. 403).

Hayek asume esta postura. Escribe: "el individualismo es un resultado necesario del nominalismo político, mientras que las teorías colectivistas tienen sus orígenes en la tradición realista o esencialista, como la denomina más apropiadamente Karl Popper" (Hayek 1986, p. 320). Y, coherentemente, sostiene que la sociedad no es más que "un conjunto de relaciones entre individuos y grupos organizados", y por ello rechaza "el erróneo antropomorfismo (que la) concibe como 'actuando' o 'deseando algo'“ (Hayek 1980, p. 11).

Hayek constata que el "individualismo" -así como los principales términos de la teoría política-, "ya no simbolizan hoy sistemas coherentes de ideas. Han llegado a describir conjuntos de principios y hechos completamente heterogéneo, que el accidente histórico ha asociado a estas palabras, pero que tienen muy poco en común" (Hayek 1986, p. 317). Otros teóricos liberales reconocen también el carácter polisémico de ésta y otras categorías de la filosofía política. Macpherson, por ejemplo, señala que "el individualismo no es un concepto monolítico. Abarca toda una gama de supuestos sobre la naturaleza esencial del hombre" (Macpherson 1991, p. 117). Al tenor de estos textos, no resulta plausible la postura de John Gray, que ha sostenido que hay una concepción individualista común a todos los teóricos liberales. "Existe una concepción definida del hombre y la sociedad, moderna en su carácter. Esta es común a todas las variantes de la tradición liberal ¿Cuáles son los elementos de esta concepción? Es individualista en cuanto afirma la primacía moral de la persona frente 
a las exigencias de cualquier colectividad social" (Gray 1994, p. 10) Esta definición de individualismo es muy general, y no corresponde tampoco a la de Hayek.

Nuestro autor diferencia dos tipos de individualismo. Mejor dicho, considera que solo hay un verdadero individualismo liberal, y el otro es falso. Y el verdadero es el centro, el "núcleo duro", -como diría Lakatos-, del "verdadero liberalismo" que Hayek y la Sociedad Mont-Pèlerin han intentado rescatar. Este sería el individualismo de John Locke, Bernard Mandeville, David Hume, Adam Smith, Edmond Burke, Alexis de Tocqueville, Lord Acton y otros.

Quizá la mayor influencia que experimenta sea la de Smith y su teoría de la autorregulación del mercado. Según ésta, los individuos producen, espontáneamente, un orden, sin tener conciencia de ello. "Más bien hubiera valido describir, quizá 'la mano invisible', como un modelo invisible e inobservable. Nosotros somos conducidos por el sistema de fijación de precios en el mercado, por ejemplo, a hacer las cosas en estas circunstancias de las cuales no tenemos, globalmente, conciencia, y que producen resultados que nosotros no hemos buscado" (Hayek 1990, p. 45).

El "falso individualismo", o "la segunda corriente estaría representada por pensadores franceses y europeos" (Hayek 1986, p. 317). Sus principales representantes serían Descartes, los enciclopedistas, Rousseau, los fisiócratas y John Stuart Mill. Este "individualismo racionalista tiende siempre a un desarrollo opuesto al señalado, específicamente hacia el socialismo y el colectivismo" (Hayek 1986, p. 318). La característica principal del verdadero individualismo, sigue exponiendo, es el de ser "primordialmente una teoría de la sociedad, un intento por conocer las fuerzas que determinan la vida social del hombre" (Ibíd). Con esta aclaración, Hayek busca disolver el malentendido que considera que el individualismo es una postura que afirma la existencia de "individuos aislados y autónomos, en lugar de entender que el carácter y naturaleza de los hombres está determinado por su existencia en la sociedad" (Hayek 1986, p. 320).

Rechaza toda teoría social que denomina "colectivista", la cual considera los conjuntos sociales como entidades en sí mismas, cuya existencia sería independiente de los individuos que la componen. Consecuente con el nominalismo, considera que fenómenos sociales solo pueden ser comprendidos mediante el entendimiento "de las acciones individuales dirigidas a otras personas y guiadas por un comportamiento esperado" (Ibíd). Su individualismo es radicalmente opuesto a lo que llama el "construccionismo", racionalista, cuyo origen se encontraría en Descartes, que sería la postura que afirma que se puede crear, conscientemente, instituciones sociales; y por ello rechaza absolutamente la idea de que el orden social corresponda a "un plan deliberado".

La diferencia principal entre ambos individualismos, el verdadero y el falso, radica, asimismo, en el papel atribuido a la razón, como se expondrá en su concepción de la racionalidad. Asimismo, rechaza que el individualismo liberal, como él lo entiende, corresponda a la concepción del "hombre económico". Hayek dice que Smith y los otros autores mencionados no supusieron nunca "un comportamiento estrictamente racional o por una falsa psicología racionalista. Desde su perspectiva, el 
hombre era por naturaleza flojo e indolente, poco previsor y derrochador, y que solo porque se vio obligado por las circunstancias, logró actuar en forma económica para ajustar sus medios a sus fines" (Hayek 1986, p. 325). Esta concepción coincide con la concepción evolucionista del hombre.

Esta posición difiere de Locke -que podría ser considerado el fundador de la concepción economicista del hombre-, puesto que éste pensaba que Dios había creado a los hombres con una racionalidad adecuada para el mercado, que podía ejercerse aun antes de que se constituyera la sociedad (Locke 1980). Smith, de modo análogo, pensaba que el hombre es un ser económico, que naturalmente tiende al intercambio económico: "hay una propensión de la naturaleza humana a permutar, cambiar y negociar una cosa por otra" (1958, p. 7). Puede decirse que los clásicos liberales consideraban como natural y real el individuo posesivo que solo estaba comenzando a realizarse históricamente. "Il s'agit plutôt d'une anticipation de la "societé civil", qui se préparait depuis la XVIe. siècle et qui, aux XVIIIe., marchait à pas de géants vers sa maturité. Dans cette société de livre concurrance, chaque individu se présent comme degagé des liens naturels, etc". (Marx 1965, p. 235). Hayek, en cambio, no cree que todos los seres humanos sean maximizadores racionales, sino que piensa que solo las elites adquirieron la racionalidad económica mediante una larga evolución histórica, y las masas solo la poseen en escasa medida, lo que explicaría su propensión al socialismo.

Hayek no menciona a Hobbes entre sus referentes, quien ha sido considerado como uno de los fundadores del liberalismo clásico (Macpherson 1970, pp. 21-97). Incluso, cuestiona su concepción del hombre natural. Sin embargo, también ha recibido su influencia en su concepción de la racionalidad como capacidad de cálculo y de la felicidad. "El continuado éxito en obtener cosas que un hombre desea de vez en cuando, es decir, el continuado prosperar, es lo que los hombres llaman felicidad, porque la vida misma no es sino movimiento, y jamás podrá ser sin deseo, ni sin temor, como no podrá ser sin sensación" (Hobbes 2003, p. 168).

John Locke formuló, inequívocamente, el principio del individualismo posesivo al sostener que Dios había creado al hombre como un propietario: "cada hombre tiene la propiedad de su propia persona. Nadie, fuera de él mismo, tiene derecho sobre ella" (Locke 1980, p. 23). Macpherson consideró el principio de la propiedad de sí mismo como uno de los supuestos principales del liberalismo clásico inglés, que funda su "individualismo posesivo". Lo formuló brevemente: "El individuo es esencialmente el propietario de su propia persona y de sus capacidades por las cuales nada debe a la sociedad" (Macpherson 1970, p. 125).

Locke afirmó, asimismo, que Dios había creado libres a los hombres; y con ello negó toda forma de dependencia tradicional, propia de la sociedad estamental feudal. Sostuvo que Dios también dotó a todos los hombres de racionalidad mercantil. Esta habría hecho posible que, antes de la creación de la sociedad y del Estado, los hombres en el estado de naturaleza, convinieron en considerar a los metales preciosos como medios generales de intercambio, creando así el dinero. Esto permitió el funcionamiento del mercado de tierras y su acumulación. Este bien fue haciéndose escaso y 
muchos quedaron privados de la posibilidad de ser propietarios labrando una porción de tierra, que era el modo primitivo de adquisición de propiedad en la fase anterior al estado de naturaleza. No tuvieron otra posibilidad que convertirse en asalariados agrícolas de los propietarios; surgió así el mercado de trabajo, y ambos mercados, requirieron del sistema de contratos.

La teoría evolucionista sobre el hombre de Hayek se basa en una reconstrucción racional de la historia, que, paradojalmente, recuerda a la realizada por Rousseau, aunque difiere en sus contenidos (1964). Los seres humanos, en su larga etapa tribal, que abarca casi toda la historia de la especie, habrían desarrollado un conjunto de instintos sociales que les permitieron alcanzar una alta cohesión grupal y, basados en la cooperación, pudieron sobrevivir a las amenazas naturales y ambientales. "El hombre existió mucho tiempo en pequeñas bandas de cazadores, que compartían sus alimentos y que mantenían un estricto orden de autoridad en un territorio común y protegido de la banda" (Hayek 1989, p. 184). Rechaza la concepción de los filósofos del siglo XVII, especialmente de Hobbes, que afirmaron que el "hombre natural" era naturalmente egoísta (Hayek 1990, p. 42). "El tipo de coordinación se basaba en los instintos de solidaridad y altruismo. Solo así podían en aquellos tiempos subsistir los miembros de esas pequeñas comunidades humanas: el individuo aislado tenía escasa posibilidades de supervivencia. El primitivo individualismo descrito por Hobbes no pasa de ser un mito" (Ibíd).

Consiguientemente, el individualismo no es de origen instintivo, sino que es el resultado del proceso civilizatorio. "Nada de individualista tiene el salvaje: su instinto es y ha sido siempre gregario. Nunca existió en nuestra planeta esa supuesta 'guerra de todos contra todos" "(Ibíd). La existencia tribal habría "determinado" la aparición de un conjunto de patrones de conducta que se habrían convertido en hereditarios: "Las necesidades de esta especie de sociedad antigua primitiva determinaron la mayor parte de las tendencias morales que aún nos gobiernan y que aprobamos en los demás. Es más que probable que la mayoría de ellos no solo han sido trasmitidos culturalmente a través de la enseñanza o de la imitación, sino que llegaron a ser innata y genéticamente determinados" (Hayek 1989, p. 184). En su último libro, denomina a estas tendencias morales "instintos del hombre" y "reflejos innatos" (Hayek 1990). Este cambio terminológico muestra que Hayek optó por la segunda opción, apoyado por la argumentación de algunos sociobiólogos que consideran el "altruismo" como uno de los "reflejos innatos" (Ibíd, p. 43). Esta opción le permitió sostener la tesis de que la creencia en la justicia social era un "atavismo" (Hayek 1989).

Este autor nos ofrece una hipótesis de explicación genética sobre dichos "instintos del hombre" y "reflejos innatos" en la sociedad tribal: "La banda poseía en efecto lo que aún atrae a tanta gente: un propósito unitario o una jerarquía común de fines, y una repartición deliberada de los recursos de acuerdo a una visión común de los méritos individuales. Estas bases de su cohesión, sin embargo, imponía también límites al posible desarrollo de esta forma de sociedad" (Ibíd, p. 184).

Esta hipotética descripción concuerda con su concepción general de que el verdadero individualismo no implica afirmar que los seres humanos son "individuos 
aislados e individuales autónomos, (sino) que el carácter y naturaleza de los hombres está determinado por su existencia en la sociedad" (1986, p. 320). Sus representaciones sobre la existencia tribal implican una ruptura con la antropología de Hobbes y Locke, para la cual el "hombre natural" era libre y cada individuo se consideraba "dueño de su propia persona y de sus capacidades, por las cuales nada debe a la sociedad" (Macpherson 1970, p. 225). Hayek, en cambio, considera que el hombre tribal era gregario y carecía de libertad: "el individuo poco podía hacer si no era aprobado por los demás. Es una ilusión pensar que en la sociedad primitiva era libre. No había libertad natural para un animal social, dado que la libertad es una creación propia de la civilización. Al individuo no se le reconocía dentro del grupo ningún poder de acción independiente" (Hayek 1989, p. 184).

Para Hayek, la existencia de las sociedades se basa en la capacidad humana de aprendizajes colectivos, la cual fue posible -y en cierta medida continúa siéndolo-, por la existencia de los referidos instintos "colectivistas" o "sociales", pues estos son necesarios para la vida familiar (Hayek 1990). Estas reglas de carácter instintivo no poseen valor moral. Sin embargo, ya en el período neolítico, según Hayek, habrían surgido conductas económicas innovadoras que dieron inicio a lo que denomina "el juego del mercado". "Cuando los primeros comerciantes neolíticos llevaron barcos cargados de hachas desde Gran Bretaña, cruzando el Canal, para intercambiarlas por ámbar y probablemente también, ya entonces, por vasijas de vino, su objetivo no era servir las necesidades de gente conocida, sino obtener mayor ganancia. Precisamente, porque solo se interesaban en quienes ofrecieran el mejor precio por sus productos, llegaron a personas que les eran completamente desconocidas, mejorando los niveles de vida de estas mucho más de lo que hubieran podido mejorar los de sus vecinos, al entregar sus hachas a aquellos que, sin duda, podrían hacer mejor uso de ellas" (Ibíd, p. 185). Posteriormente, dice que se desarrollaron ciudades independientes, se supone a orillas del Mediterráneo, de carácter comercial: "El cambio ocurrió en los nuevos centros urbanos de comercio y artesanía, que se desarrollaron en puertos o cruces de rutas comerciales, donde los hombres que habían escapado a la disciplina de la moral tribal establecieron comunidades comerciales y desarrollaron gradualmente las nuevas reglas del juego de la catalaxia (mercado)" (Hayek 1989, p. 186). Se trata de una nueva versión de la tesis del carácter civilizatorio del comercio, que ya aparece en los ilustrados franceses, especialmente en Voltaire (1959).

Desde entonces, se produce un largo proceso hasta llegar a la sociedad de mercado, que Hayek denomina "orden extendido", la cual constituye la fase final del desarrollo de la humanidad. Cree que dicha evolución fue posible, tanto en el ámbito de la biología como de la sociedad, porque existe una tendencia espontánea hacia el progreso, en el sentido del desarrollo de una creciente capacidad de adaptación en la lucha por "la supervivencia de los más eficaces en el aspecto reproductivo" (Hayek 1990, p. 62).

El hombre es un ser creador de normas y tradiciones. Hayek piensa que el hombre se diferencia de los animales, los cuales actúan solo guiados por los instintos, por una doble capacidad. De una parte, de acción consciente instrumental, y de otra por poseer una capacidad espontánea, y que no requiere plena conciencia, de crear 
y cumplir normas y tradiciones sociales, las que son la base de la vida social. Esta capacidad se basa en el desarrollo de habilidades mediante aprendizaje colectivo e imitación, y en la capacidad de transmitirlas culturalmente. La vida social en la cual los seres humanos se comprenden, conviven y logran realizar con éxito sus planes requiere que los miembros de la sociedad actúen de acuerdo con regularidades no conscientes.

Esta caracterización difiere de la tradición racionalista que considera, desde Aristóteles, la racionalidad como diferencia específica, animalis rationalis, y como la facultad humana por excelencia. Hayek, en cambio, asevera que la racionalidad es el resultado del proceso evolutivo, y que éste ha permitido a los seres humanos adquirir las referidas habilidades. En su última obra escribe: "Tal vez la cualidad más importante del legado genético de cada individuo, aparte de las respuestas innatas sea la posibilidad de acceder ciertas habilidades por la imitación y el aprendizaje. De ahí la importancia de precaverse contra cualquier planteamiento proclive a lo que he llamado "la fatal arrogancia": esa idea de que solo por vía de la razón pueden adquirirse nuevas habilidades (Hayek 1990, p. 54).

$\mathrm{Su}$ tesis es que las tradiciones son las que han permitido construir la "gran sociedad" contemporánea. Escribe: "el hombre devino inteligente porque dispuso previamente de ciertas tradiciones - que ciertamente hay que emplazar entre el instinto y la razón-, a las que pudo ajustar su conducta" (Ibíd, p. 42). Las tradiciones se originan en normas sociales exitosas. El surgimiento de las nuevas normas se debería a la pérdida de funcionalidad de las anteriores que solo eran adecuadas para una pequeña sociedad. La civilización, que culmina en "la sociedad extendida", sería el resultado de la historia de la progresiva supresión de las normas instintivas, y su sustitución por normas impersonales de coordinación de grupos humanos más amplios que el del grupo tribal de origen. Las nuevas normas de comportamiento humano "plasmadas por vía evolutiva (y especialmente las que se refieren a la propiedad plural, al recto comportamiento, el respeto a las obligaciones adquiridas, el intercambio, la competencia, el beneficio y la inviolabilidad de la propiedad privada) son las que generan tanto la íntima estructura como el tamaño de la población actual” (Hayek 1990, p. 42).

A diferencias de los instintos sociales tribales, éstas son reglas que posibilitan la existencia de "una sociedad abierta y abstracta, en la cual resulta un orden de individuos que observan las mismas reglas abstractas del juego, mientras usan su propio conocimiento en la búsqueda de sus propios fines" (Hayek 1989, p. 186). Su carácter abstracto se manifestaría en el hecho de que la conducta de los individuos se coordina, espontáneamente, con muchas otras personas que no conocen, y a las cuales sirven, y se benefician con los resultados de sus acciones. La evolución de las normas no se ha producido de modo uniforme en todas las sociedades, mientras algunas están más cerca de ser plenamente "sociedades extendidas" o "sociedades abiertas", como también se las denomina; otras están aún lejos o en proceso de serlo.

Las normas morales son heterónomas y corresponden a las condiciones de reproducción de la sociedad extendida. Kant distingue entre las éticas heterónomas y autónomas. La voluntad heterónoma no se da a sí misma la ley moral, sino que la 
extrae de la sociedad o de la religión. La acción guiada de dicha ley no constituye una decisión ética libre, pues carece de autonomía, que para Kant es el único principio de la ética.

La opción teórica de Hayek es claramente heteronómica: las reglas morales corresponden a las mencionadas normas sociales de la sociedad extendida. Todas ellas constituyen condiciones de posibilidad y reproducción de la sociedad de mercado y son reglas morales inmanentes y necesarias para su mantención y reproducción. La honestidad se refiere especialmente al respeto irrestricto a la propiedad privada y a los contratos. De este modo, Hayek sostiene que ha sido el surgimiento de las normas del mercado lo que ha civilizado a los seres humanos y les ha permitido evolucionar desde la vida tribal a la "sociedad extendida". Podría decirse que considera la actividad económica como constitutiva de lo social, sin embargo, éste no se reduce a lo económico, sino que tiene dimensiones jurídicas y políticas. "No es mera coincidencia el que muchas de las normas abstractas, por ejemplo, las relativas a la propiedad plural y la responsabilidad personal, giren en torno a cuestiones de carácter estrictamente económico. Desde sus orígenes, la economía se ha ocupado de analizar cómo surge un orden extenso de interacción humana cuyo contenido supera siempre nuestra limitada capacidad de percepción y diseño" (Hayek 1990, p. 45). En síntesis, sostuvo que todas las normas y tradiciones constituyen "un orden social autogenerado".

Hayek otorga relevancia a las reglas morales: "de todas estas convenciones y costumbres (human intercourse), las reglas morales son las más importantes, aunque no en absoluto las únicas significativas" (Hayek 1980, p. 62). Ellas permiten la coordinación espontánea de las acciones humanas porque habitualmente son "inconscientes patrones de conductas producto de hábitos y tradiciones firmemente establecidos que no son el resultado de mandatos o coacción, y a menudo ni siquiera de ninguna adhesión consciente a reglas conocidas, sino producto de hábitos y tradiciones firmemente establecidas. La coacción puede evitarse porque existe un alto grado de conformidad voluntaria" (Ibíd). Dicha coacción y presión debe ser moderada para permitir la aparición y desarrollo de nuevas normas innovadoras. Esta postura es opuesta a la de la Ilustración, la cual había visto como fundamento de la autonomía práctica a la racionalidad, entendida como saber crítico sobre las relaciones sociales y las normas morales (Vergara 2004, pp. 171-172).

Estas reglas operan, aunque no conozcamos su significado, a pesar de que ni siquiera seamos conscientes de que existen, y por ello debemos respetarlas incondicionalmente. "Esta reverencia por lo tradicional, indispensable para el funcionamiento de la sociedad libre, es lo que el tipo de mente racionalista encuentra tan incompatible" (Hayek 1971, p. 63). La razón no podría someterlas a examen, puesto que ellas son un presupuesto de la razón y no su resultado. Ellas realizan "el sistema de valores dentro del cual hemos nacido, éste suministra los fines que nuestra razón debe servir" (Ibíd). Sostiene que la libertad no puede ejercerse sin la existencia de profundas creencias morales. Hace suya la idea de Burke que dice que "la idoneidad de los humanos para la libertad civil está en relación directa con la disposición de atar con cadenas morales sus apetitos" (cit. Hayek 1980, p. 62). 
La razón es limitada y no puede determinar fines. La primera idea central para comprender la concepción de razón de Hayek es negativa. No puede atribuirsele el progreso del hombre a lo largo de la historia, sino que éste se debe a la creación espontánea de normas y tradiciones, como se expuso precedentemente. Hayek desarrolla una concepción también negativa del conocimiento: casi todos nuestros conocimientos, especialmente los referidos a las interacciones sociales, no provienen de experiencias inmediatas, ni de aprendizajes sistemáticos, sino de tradiciones transmitidas que no son justificables racionalmente. Para Hayek, el mundo es incognoscible como una totalidad, no podemos conocer sino fragmentos. El mundo incluye el cambio, hay que adaptarse constantemente, y cada individuo accede solo a un punto de vista particular, a una información, pero jamás a la información completa. En general, Hayek considera que el verdadero individualismo "asigna un papel más bien menor a la razón en los asuntos humanos” (Hayek 1989, p. 322). El falso individualismo, en cambio, muestra una "confianza exagerada en los poderes de la razón individual y un desprecio consecuente hacia todo lo que no ha sido ideado conscientemente por ella, o que no sea completamente comprensible" (Ibíd). Este segundo tipo de pensamiento es "el argumento racionalista, verosímil (plausible) y aparentemente lógico de la tradición francesa, con su halagadora presunción sobre los poderes ilimitados de la razón humana, ganó progresiva influencia” (Hayek 1980, p. 54).

El principio de la limitación del conocimiento humano proviene de la filosofía medieval. Aparece claramente formulado por Tomás de Aquino en la distinción entre el orden de la fe y de la razón. Opone el principio de la omnisciencia de Dios a la finitud del conocimiento humano, y éste no puede conocer solo con la "luz natural" los principales dogmas de la fe. Fue reformulado el siglo pasado por Weber, Popper y Hayek, como criterio de discernimiento de la acción social: es imposible realizar cualquier acción social que implique conocimiento ilimitado (perfecto). Sin embargo, este juicio sería apodíctico. "Toda acción humana está limitada por el hecho de que el conjunto de los conocimientos humanos no es centralizable en un sola instancia" (Hinkelammert 1984, p. 160). En este mismo sentido, Hayek señala que el conocimiento "solo existe en la forma dispersa, incompleta e inconsistente que aparece en muchas mentes individuales, e (implica) la dispersión e imperfección de todo el conocimiento" (Hayek 2002, p. 56).

Para Hayek esta limitación se refiere específicamente a la imposibilidad de conocer cómo funcionan las tradiciones heredadas o "Self-genereting Orders", como las llama: la moral, el derecho, la economía, el lenguaje y otras, las cuales "no pueden justificarse a partir de bases estrictamente racionales (en el tradicional sentido de la palabra)" (Hayek 1990, p. 130). Nuestras normas morales no serían el resultado de la razón, sino del desarrollo evolutivo, así como la razón misma, aunque su desarrollo evolutivo sea diferente. Tampoco serían productos de la razón los valores sociales, sino también de la selección evolutiva, por tanto de la competencia entre distintos valores, de los cuales han subsistido aquellos que han hecho más exitosos a los grupos humanos que los poseen (Ibíd, pp. 71-84).

En su opinión, se ha otorgado demasiada importancia al conocimiento de los expertos, cuyo saber está fundado sobre la teoría económica, y se cree que éste es el 
único conocimiento en está área. Pero, dice que hay otro conocimiento que no está organizado, ni es sistemático. Este es "el conocimiento de las circunstancias particulares de tiempo y lugar que le otorgan a quien lo posee una cierta información única que puede utilizar si se le deja tomar decisiones que dependen de esa información" (Hayek 1983, p. 157).

La libertad es individual, abstracta y negativa. Este es un tema central de la concepción del hombre, pues Hayek ha definido su pensamiento como una "filosofía de la libertad". Otorga a su reflexión un carácter restaurador del verdadero sentido de la libertad. "En los países de Occidente, el acuerdo sobre ciertos valores fundamentales ya no es explícito, y si aquellos valores han de recuperar todo su vigor, es urgente e ineludible restaurarlos y reivindicarlos sin reservas" (Hayek 1960, p. 3).

Ya se han expuesto los argumentos con que Hayek rechaza la concepción de los clásicos liberales de la existencia de una "libertad natural". En la existencia tribal no hay libertad individual; ella es posible solo en una sociedad extendida, y en el marco del estado de derecho. Hayek realiza una deconstrucción del concepto de libertad, del cual va abstrayendo diversas dimensiones: (a) la de la libertad interior e intelectual para evitar que se debilite la creencia de la responsabilidad individual; (b) la política, puesto que el pleno ejercicio de la libertad individual no la requiere; por ello, señala que "un pueblo de hombres libres no es necesariamente un pueblo libre. Nadie necesita participar de dicha libertad colectiva para ser libre" (Ibíd, p. 13), es decir un pueblo podría ser dependiente o una colonia, sin embargo, sus habitantes podrían ser libres si existiera libertad económica individual; (c) la dimensión social, puesto que la libertad es estrictamente individual, y no se refiere a colectivos, grupos o pueblos; (d) la dimensión del poder; Hayek rechaza el concepto de Dewey de la libertad-poder, pues dice que la libertad no es una capacidad de hacer, no tiene relación alguna con las posibilidades reales de acción, ni tampoco con la riqueza: "es indudable que ser libre puede significar libertad para morir de hambre, libertad para incurrir en costosas equivocaciones, para correr en busca de riesgos mortales" (Hayek 1960, p. 18).

Sostiene que el concepto de libertad es negativo, es decir, la define como ausencia de coerción ilegítima e intencionada que puede provenir del Estado o de grupos privados. Somos libres en todo lo que no se nos impide hacer, y su ámbito de ejercicio por excelencia es el mercado. "el concepto de libertad es negativo. Lo que se llama libertad positiva, que permite a algunos gozar el derecho para hacer cosas especiales, es irreconciliable con la idea de igualdad ante la ley" (Hayek 2000, p. 48). Hayek señala que la libertad es o se basa en la libertad económica que incluye la libertad intelectual. "No puede separarse la libertad económica de otras libertades. La libertad consiste en experimentar y solo se puede experimentar si se pueden usar todos los medios a los cuales se tiene acceso. La distinción entre libertad económica y libertad intelectual o cultural es artificial. No existe un sistema que, privando de la libertad económica, haya podido garantizar la libertad individual" (Ibíd, pp. 49 y 50).

La libertad tiene íntimas relaciones con la moral, como se ha expuesto. Para Hayek la libertad debe guiarse siempre por las reglas y tradiciones sociales, morales 
y económicas, pues de ellas depende la mantención de la civilización, y si se producen trasgresiones, la coerción es necesaria. "Para el individuo, la libertad significa que él sabe de antemano las reglas que debe obedecer para no ser coaccionado por el gobierno" (Hayek 2000, p. 48). La existencia de profundas tradiciones morales es condición de la libertad. Hayek se pregunta por qué queremos la libertad. Su respuesta es que "el ideal de libertad inspiró la moderna civilización occidental y hizo posible sus efectivos logros" (Hayek 1960, p. 1). Esto muestra que para Hayek lo fundamental es el progreso civilizatorio, y la libertad es valiosa por su contribución a éste. Por eso considera que la libertad no implica egoísmo, ni necesariamente bienestar individual, sino que su ejercicio constituye un aporte a la reproducción y desarrollo de la sociedad abierta. Esta concepción funcional se manifiesta en una cita de H. B. Phillips que precede a la Primera Parte de Los fundamentos de la libertad. "La libertad se concede a los individuos no en razón de que les proporcione una mayor satisfacción, sino porque el término medio de ellos servirá al resto de nosotros mejor que si cumpliera cualquier clase de órdenes que supiéramos darles" (Hayek 1960, p. 9). Esta última frase está inspirada en la idea de Adam Smith de que siguiendo las leyes del mercado, cada uno contribuye, sin proponérselo, al interés de todos.

Los hombres son desiguales. La reflexión de Hayek sobre la igualdad tiene tres aspectos centrales: (a) su tesis de la desigualdad natural de los hombres; (b) las legítimas desigualdades económicas, y (c) las igualdades funcionales.

Hayek sostiene que cada ser humano es un conjunto único de atributos, producto de una combinación única de genes de donde proviene. Y esta unicidad biológica es reforzada por las diferencias de educación y formación. Estas diferencias se expresan en la distinta capacidad adaptativa a la vida práctica, especialmente al mercado. Los seres humanos se dividen en la mayoría y la minoría. La primera "constituye la masa", los menos originales y menos independientes, cuya fuerza reside en el número. Ellos son "insuficientemente civilizados", y se guían por los "atavismos". Este término del léxico biológico significa "tendencia en los seres vivos de reaparición de caracteres propios de sus ascendientes más o menos remotos" (Diccionario de la Real Academia 1992, p. 221). Estas serían las reglas sociales arcaicas de la sociedad tribal, basadas en la solidaridad (Hayek 1989). Las masas no comprenden las reglas y las leyes abstractas que rigen la sociedad extendida. Por eso, no logran adaptarse de manera adecuada a la competencia. La minoría, en cambio, posee todas las capacidades de las que carecen las masas. Son enteramente civilizadas, pueden comprender y aplicar las reglas abstractas que rigen la vida social y el mercado. Por ello obtienen éxito en la vida práctica y en el mercado.

Consecuentemente, sostiene que, en una sociedad de mercado, las desigualdades sociales y económicas son una consecuencias esperable y deseable del ejercicio de la libertad y de la competencia en el mercado entre individuos desiguales". La libertad no tiene nada que ver con cualquier clase de igualdad, sino que produce desigualdades en muchos aspectos. Se trata de un resultado necesario que forma parte de la justificación de la libertad individual" (Hayek 1960, p. 85). Así mismo, cree que la pasión por la igualdad es una forma de envidia. 
A su parecer, la existencia de diversas formas de desigualdad entre los seres humanos no implica que deban ser tratados en forma desigual. Al contrario, en una sociedad extendida es adecuado tratar a los seres humanos de la misma manera. Esto implica el reconocimiento de la igualdad ante la ley, la justicia y el mercado, todas las cuales son formas de igualdad funcionales a la reproducción de la sociedad de mercado. "Es esencial afirmar que se aspira a la igualdad de trato, no obstante el hecho cierto de que los hombres son diferentes. Ha constituido el gran objetivo de la lucha por la libertad conseguir la implantación de la igualdad de todos los seres humanos ante la ley" (Hayek 1960, pp. 85-86).

Podemos extraer varias conclusiones de este análisis de la antropología hayekiana. La primera, es que ésta, aunque comparte algunos de sus principios fundamentales, sin embargo tiene diferencias significativas con la antropología de los clásicos liberales. Esto permite cuestionar la tesis de la continuidad entre el liberalismo clásico, sostenida tanto por Hayek como Macpherson, aunque de modos diferentes. En primer lugar, respecto a la igualdad, pues los clásicos ingleses afirman el principio de la igualdad de todos los hombres, y no solo la igualdad natural del estado presocial. También hay diferencias respecto a la racionalidad económica. Locke y Smith creen que Dios ha creado a todos los hombres dotándolos de racionalidad económica, Hayek, en cambio, sostiene que solo la poseen plenamente los miembros de la minoría.

En segundo lugar, cabe preguntarse sobre el carácter de esta antropología. De una parte, el autor asume ciertos supuestos y principios sin haberlos argumentado suficientemente, por ejemplo, su concepción de la desigualdad humana. De otra, constatamos la presencia de enunciados normativos que predominan sobre los explicativos. Esto podría relacionarse con la ausencia de diálogo y debate o el rechazo de otras concepciones antropológicas relevantes, como el psicoanálisis, el liberalismo comunitario o la de Ricoeur. "Hegel, Marx y Freud son los representantes más conspicuos del camino equivocado" (Hayek 2000, p. 59).

Tercero, su concepción de la evolución de la humanidad está centrada casi exclusivamente en el tema del desarrollo de las relaciones mercantiles, y en menor medida, de las normas sociales y jurídicas, y apenas incluye algunos aspectos intelectuales, políticos y culturales. Pareciera que para Hayek el elemento central del desarrollo civilizatorio es el desarrollo del mercado. Relacionado con esto, constatamos que en su obra no hay una reflexión sobre la modernidad. Se diría, con Weber y Giddens, que su evolucionismo concibe de modo continuo el desarrollo histórico y no reconoce las profundas discontinuidades entre la sociedad moderna y la tradicional (Giddens 1997).

Cuarto, podría decirse que la concepción individualista de Hayek resulta paradójica, puesto que afirma que es una teoría social determinista: "primordialmente una teoría de la sociedad, un intento por conocer las fuerzas que determinan la vida social del hombre" (Hayek 1986, p. 318). Como se ha mostrado a través de este análisis, Hayek privilegia siempre el funcionamiento de las instituciones de la sociedad de mercado, e incluso llama a aceptar con devoción las reglas y tradiciones sociales. En 
ese sentido, se podría decir que nos encontramos, paradójicamente, frente a una antropología societalista. Asimismo, su concepción del individualismo difiere nítidamente de otras concepciones individualistas modernas, como la de Kant y Stuart Mill, basadas en el concepto de autonomía moral y social, así como en el de autodesarrollo.

Quinto, Hayek no reconoce, como muchas otras teorías filosóficas y sociales, una tensión entre individuo y sociedad en la sociedad moderna, como lo hace Weber, Giddens, Habermas y otros, ni tampoco encontramos una reflexión sobre la relación entre institucionalidad y subjetividad.

Sexto, su concepción de la libertad aparece demasiado limitada y centrada en los aspectos económicos. A diferencia de Kant y de Stuart Mill, para los cuales la libertad de pensamiento y de expresión tenía una importancia central para el desarrollo de la personalidad y de la libertad, Hayek insiste en la aceptación de las reglas y tradiciones, aunque no sepamos cómo funcionan, y pareciera reducir la libertad intelectual a la posibilidad de experimentar en lo económico. Esta opinión no es compartida por los principales teóricos sociales contemporáneos: Weber, Habermas, Giddens, Hinkelammert y otros que han ofrecido significativas y comprensivas interpretaciones sobre el funcionamiento de las principales instituciones sociales.

\section{Referencias bibliográficas}

Giddens, Anthony (1997), Las consecuencias de la modernidad. Madrid: Alianza Editorial.

Gray John (1994), Liberalismo. Madrid: Alianza Editorial.

Habermas Jürgen (196), “Conocimiento e interés”, Ciencia y técnica como "ideología”. Madrid: Ed. Tecnos.

Hayek, Friedrich (1960), The Constitution of Liberty. London: The University of Chicago Press.

(1980), "El ideal democrático y la contención del poder”, Estudios Públicos. 1: 11-75.

(1983), "El uso del conocimiento en la sociedad", Estudios Públicos. 12: $157-169$. 315-341.

(1986), "El individualismo: verdadero y falso", Estudios Públicos. 22:

(1989), "El atavismo de la justicia social”, Estudios Públicos. 36: 181193.

(1990), La fatal arrogancia. Los errores del socialismo. Santiago: Centro de Estudios Públicos.

(2002), "Friedrich von Hayek" (entrevista), en Lucía Santa Cruz, Conversaciones con la libertad. Santiago de Chile: El Mercurio-Aguilar, pp. 4159. 
(2002), La contrarrevolución de la ciencia. Madrid: Unión Editorial.

Heidegger, Martin (1958), La época de la imagen del mundo. Santiago: Ed. Anales de la Universidad de Chile.

Hinkelammert, Franz (1984), Crítica de la razón utópica. San José de Costa Rica: DEI.

Hobbes, Thomas (2003), Leviatán. Buenos Aires: Ed. Losada.

Husserl, Edmund (1984), La crisis de las ciencias europeas y la fenomenología trascendental. México: Ed. Folios.

Leckachman, Robert (1970), La era de Keynes. Madrid: Alianza Editorial.

Locke, John (1980), Segundo ensayo sobre el gobierno civil. Madrid: Ed. Aguilar.

Macpherson, Crawford (1970), La teoría politica del individualismo posesivo. Madrid: Ed. Fontanella.

(1991), Ascenso y caída de la justicia económica y otros ensayos. Buenos Aires: Ed. Manantial.

Marx Karl, 1965, "Introduction générale a la critique de l'économie politique", Euvres, Economie I. Paris: Éditions Gallimard.

Popper, Karl (1981), La sociedad abierta y sus enemigos. Barcelona: Ed. Paidós.

(1989), Conjeturas y refutaciones. El desarrollo del conocimiento científico. Barcelona: Ed. Paidós.

Rousseau, Jean-Jacques (1964), Discours sur l'origine et le fondement de la inégalité, Oeuvres completes, tomo III. París: Ed. Gallimard.

Smith, Adam (1958), Investigación sobre la naturaleza y causa de la riqueza de las naciones. México: Ed. F. C. E.

Vergara, Jorge (2004), "La contribución de Popper a la teoría neoliberal", en Félix Schuster (ed.)., Popper y las ciencias sociales, Buenos Aires: Editores América Latina.

(2005), L'utopie néolibéral et ses critiques, Tesis de Doctorado en Filosofía. París: Universidad de París VIII (inédita).

(2007), "La democracia neoliberal en Chile", La política en la era de la globalización. Santiago: Cuarto Propio.

Voltaire (1959), Ensayo sobre las costumbres y el espíritu de las naciones. Buenos Aires: Ed. Hachette. 